\title{
Thonon-les-Bains - Place de Crête et chemin des Marmottes
}

Christophe Landry

\section{QpenEdition Journals}

Édition électronique

URL : http://journals.openedition.org/adlfi/14970

ISSN : 2114-0502

Éditeur

Ministère de la culture

Référence électronique

Christophe Landry, "Thonon-les-Bains - Place de Crête et chemin des Marmottes », ADLFI.

Archéologie de la France - Informations [En ligne], Rhône-Alpes, mis en ligne le 29 mai 2015, consulté le 01 mai 2019. URL : http://journals.openedition.org/adlfi/14970

Ce document a été généré automatiquement le 1 mai 2019.

(c) Ministère de la Culture et de la Communication, CNRS 


\title{
Thonon-les-Bains - Place de Crête et chemin des Marmottes
}

\author{
Christophe Landry
}

Code INSEE de la commune : 74281

Lien Atlas (MCC) :

http://atlas.patrimoines.culture.fr/atlas/trunk/index.php?

ap_theme=DOM_2.01.02\&ap_bbox $=6.439 ; 46.344 ; 6.516 ; 46.405$

1 Le diagnostic mené en décembre en préalable à l'extension d'une résidence pour personnes âgées a permis de confirmer l'absence de toute occupation antérieure au XIX ${ }^{e} s$. sur les parcelles explorées. Les seuls éléments anthropiques mis au jour correspondent à des remblais datant de la seconde moitié $d u x^{e}$ s. et à la fondation d'un mur matérialisant une limite de propriété dans la partie nord de ce terrain qui couvre une surface de $1600 \mathrm{~m}^{2}$. La maçonnerie en question figure sur le cadastre français de 1873, mais n'existe pas encore au XVIII ${ }^{\mathrm{e}} \mathrm{s}$. lors de l'établissement de la mappe sarde.

2 La terrasse tardi-würmienne apparait entre $0,40 \mathrm{~m}$ et $0,85 \mathrm{~m}$ de profondeur selon les sondages, recouverte d'un niveau d'altération dont l'épaisseur n'excède pas $0,50 \mathrm{~m}$. Il ressort de cette intervention préventive que les trois sépultures non datées, exhumées en 2009 à l'emplacement de l'actuel parking, appartiennent à un petit espace funéraire qui ne s'étend ni au sud ni à l'ouest. Dans l'hypothèse où d'autres défunts ont été inhumés plus à l'est, les témoins ne peuvent être conservés, car la parcelle voisine a déjà subi des terrassements lors de la construction d'une maison individuelle. 
INDEX

Index géographique : Rhône-Alpes, Haute-Savoie (74), Thonon-les-Bains

operation Opération préventive de diagnostic (OPD), 2013 - nºA : 2211413

AUTEURS

CHRISTOPHE LANDRY

Inrap 